\title{
Hospital volume and 1-year mortality after treatment of intracranial aneurysms: a study based on patient registries in Scandinavia
}

\author{
Haakon Lindekleiv, MD, PhD, ${ }^{1}$ Ellisiv B. Mathiesen, MD, PhD, ${ }^{2,3}$ Olav H. Førde, MD, PhD, ${ }^{1}$ \\ Tom Wilsgaard, $\mathrm{PhD},{ }^{1}$ and Tor Ingebrigtsen, $\mathrm{MD}, \mathrm{PhD}^{2,3}$
}

Departments of ${ }^{1}$ Community Medicine and ${ }^{2}$ Clinical Medicine, Faculty of Health Sciences, University of Troms $\emptyset$; and ${ }^{3}$ University Hospital of North Norway, Tromsø, Norway

OBJECT The object of this study was to examine the relationship between hospital volume and long-term mortality after treatment of intracranial aneurysms.

METHODS The authors identified patients treated for intracranial aneurysms between 2002 and 2010 from patient registries of Denmark, Norway, and Sweden, and linked to data on 1-year mortality from the population registry of each country. Cox regression models were used to relate hospital volume to the risk of death and adjusted for potential confounders (age, sex, year of treatment, Charlson comorbidity index, country, and surgical treatment).

RESULTS The authors identified 5773 patients with ruptured and 1756 patients with unruptured intracranial aneurysms, treated at 15 hospitals. One-year mortality rates were $15.6 \%$ for patients with ruptured aneurysms and $2.7 \%$ for patients with unruptured aneurysms. No consistent relationship was found between hospital volume and 1-year mortality for ruptured aneurysms in the unadjusted analyses, but higher hospital volume was associated with increased mortality in the analyses adjusted for potential confounders (hazard ratio [HR] per 10-patient increase 1.04, 95\% $\mathrm{Cl} 1.00-1.07$ ). There was a trend toward a lower mortality rate in higher-volume hospitals after treatment for unruptured intracranial aneurysms, but this was not statistically significant after adjustment for potential confounders (HR per 10-patient increase $0.69,95 \% \mathrm{Cl} 0.42-1.10)$. There were large variations in mortality after treatment for both ruptured and unruptured intracranial aneurysms across hospitals and between the Scandinavian countries $(p<0.01)$.

CONCLUSIONS The findings in this study did not confirm a relationship between higher hospital volume and reduced long-term mortality after treatment of ruptured intracranial aneurysms. Prospective registries for evaluating outcomes after aneurysm treatment are highly warranted.

http://thejns.org/doi/abs/10.3171/2014.12.JNS142106

KEY WORDS intracranial aneurysm; surgery; endovascular treatment; vascular disorders; rupture; hospital volume; Scandinavia

$\mathrm{E}$ VIDENCE that mortality after complex surgical procedures is lower at high-volume centers has led to suggestions that these surgeries should be centralized to high-volume centers. ${ }^{5,11}$ However, there is substantial heterogeneity in the results and hospital volume may not be a valid proxy for quality of care..$^{9,10}$

Studies of hospital volume and mortality after treatment for ruptured and unruptured intracranial aneurysms indi- cate a general trend toward better results at higher-volume hospitals. ${ }^{1-4,7,8,12-14,16-18}$ However, all studies except 2 were from US patient administrative databases, ${ }^{1-4,7,8,13,14,16,18}$ and the findings may not be generalizable to health care systems in other countries where specialist neurosurgical services are delivered at tertiary regional hospitals with a defined population and patients are referred from smaller hospitals. Furthermore, most studies have only examined

ABBREVIATIONS $\mathrm{CCl}=$ Charlson Comorbidity Index; $\mathrm{Cl}=$ confidence interval; $\mathrm{HR}=$ hazard ratio; $\mathrm{ICD}-10=$ International Classification of Diseases, 10 th revision; NCSP = NOMESCO Classification of Surgical Procedures; SAH = subarachnoid hemorrhage.

ACCOMPANYING EDITORIAL See pp 629-630. DOI: 10.3171/2014.12.JNS142758.

SUBMITTED September 8, 2014. ACCEPTED December 4, 2014.

INCLUDE WHEN CITING Published online July 10, 2015; DOI: 10.3171/2014.12.JNS142106.

DISCLOSURE The authors report no conflict of interest concerning the materials or methods used in this study or the findings specified in this paper. 
death at discharge. ${ }^{1-4,7,8,12-14,16,18}$ Data collection on the relationship between hospital volume and long-term mortality is highly warranted. This topic is of increasing interest as open surgeries for intracranial aneurysms are being replaced by endovascular procedures.

In this study we examined the relationship between hospital volume and 1-year mortality after surgical and endovascular treatment for ruptured and unruptured intracranial aneurysms in hospitals across Denmark, Norway, and Sweden.

\section{Methods \\ Study Population}

Scandinavia consists of the 3 countries Denmark, Norway, and Sweden, with a combined population of 19.5 million inhabitants. All neurosurgical and endovascular treatments of intracranial aneurysms are regionalized to public hospitals with neurosurgical departments. Patients with verified aneurysmal subarachnoid hemorrhage (SAH) are usually accepted for immediate admission to one of the hospitals with neurosurgical service, independent of age and clinical condition. The exceptions are patients considered in a moribund state after exclusion of acute hydrocephalus by $\mathrm{CT}$.

\section{Data Source}

The patient registries of Denmark, Norway, and Sweden contain data on all inpatient care in each respective country. We collected data from the patient registries on all patients $\geq 18$ years old with a national identity number who were admitted to hospitals in Denmark, Norway, and Sweden. We included patients admitted from January 1, 2002, to December 31, 2010, in Denmark and Sweden. For Norway, we included patients admitted from January 1, 2008 , to December 31,2010. This difference in dates was because the Norwegian hospital discharge registry only included person-identifiable data from 2008 onwards. The study was approved by the Regional Committee for Medical and Health Research Ethics North in Norway, and by the patient registries of Denmark, Norway, and Sweden.

\section{Inclusion Criteria for Ruptured Intracranial Aneurysm}

We included 5773 patients $\geq 18$ years of age with an emergency admission, a discharge diagnosis of SAH (International Classification of Diseases, 10th revision [ICD10] codes I60.0-I60.7 and I60.9), and a procedure code for surgical or endovascular treatment of an intracranial aneurysm (NOMESCO Classification of Surgical Procedures [NCSP] codes AAC00-AAC15 [surgery] and AAL00 [endovascular]).

\section{Inclusion Criteria for Unruptured Intracranial Aneurysm}

We included 1807 patients $\geq 18$ years of age with a planned admission, a discharge diagnosis of unruptured intracranial aneurysm (ICD-10 code I67.1), and a procedure code for surgical or endovascular treatment of an intracranial aneurysm (NCSP codes AAC00-AAC15 [surgery] and AAL00 [endovascular]). We excluded 51 patients with prior SAH (secondary discharge diagnosis of sequelae of
SAH, ICD-10 code I69.1, or prior admission for ruptured intracranial aneurysm in our dataset) to reduce the possibility that recovery from previous SAH would affect the results. This left 1756 patients with unruptured intracranial aneurysms available for analysis.

\section{Data Collection}

For each patient we collected the following data: age, sex, dates of admission and discharge, primary and secondary diagnosis codes, procedure codes, and hospital. Based on the secondary diagnoses, we calculated the Charlson Comorbidity Index (CCI), a widely used measure for classifying comorbid conditions that alter the risk of death. ${ }^{6}$ For patients with repeat admissions, we used the data from the first admission.

We obtained data on date of death for each patient up to December 31, 2011, by linkage of the hospital discharge registry and the population registry in each respective country, using the patient's unique personal identification number. Record linkage was conducted at each patient registry. Follow-up duration was set at 12 months after the date of admission or until death occurred within the 12-month follow-up period.

\section{Statistical Analysis}

We calculated descriptive statistics for patients with ruptured and unruptured intracranial aneurysms separately. For each hospital, we calculated average annual volume of patients and 1-year mortality rates. We used the Kruskal-Wallis test to examine whether mortality differed across year of admission, hospital, and country. We used Poisson regression to calculate age-adjusted 1-year mortality for each hospital and plotted the age-adjusted 1-year mortality for each hospital against the average annual volume of patients in the corresponding hospital.

We used Cox regression analysis to calculate hazard ratios (HRs) and 95\% confidence intervals (CIs), with time until death as the dependent variable. We assessed hospital volume as a continuous variable and as a categorical variable in 3 tertile groups. For ruptured intracranial aneurysms, the 3 tertile groups were: 5 hospitals in the lowest tertile (6.2-36.0 patients per year); 5 hospitals in the intermediate tertile (43.8-62.4 patients per year); and 5 hospitals in the highest tertile (63.1-118.0 patients per year). For unruptured intracranial aneurysms, the 3 tertile groups were: 5 hospitals in the lowest tertile (2.9-10.9 patients per year); 5 hospitals in the intermediate tertile (14.3-19.7 patients per year); and 5 hospitals in the highest tertile (21.9-45.6 patients per year). The $p$ value for trend was calculated by entering the categorical variable of hospital volume as a continuous variable in the regression models. The analyses were performed unadjusted and adjusted for age, sex, surgical treatment, CCI, year of treatment, and country. We fitted age as a continuous variable, sex and surgical treatment as dichotomous variables, and CCI $(0,1$, or 2$)$, country (Denmark, Norway, and Sweden), and year of treatment as categorical variables. The proportional hazards assumption was verified using Schönfeld's residuals and by inspection of log-log plots.

All analyses were preplanned and conducted separate- 
ly for patients with ruptured and unruptured intracranial aneurysms. We had also planned to use propensity-score matching to compare mortality rates between patients treated at low- and high-volume hospitals, but the low number of patients treated at low-volume hospitals precluded these analyses. As data from Norwegian hospitals were first available from 2008, we performed additional analyses restricted to patients admitted between 2008 and 2010. We used a 5\%, 2-sided level of significance and analyzed the data with STATA (version 12, StataCorp).

\section{Results}

We included 5773 patients treated for ruptured intracranial aneurysms and 1756 patients treated for unruptured intracranial aneurysms from a total of 15 hospitals in Denmark, Norway, and Sweden between 2002 and 2010. Baseline characteristics of the patients are given in Table 1 . The average annual volume for each hospital is given in Fig. 1. The average annual number of treatments varied from 6.2 to 118 patients per year for ruptured intracranial aneurysms and from 2.9 to 45.6 patients per year for unruptured intracranial aneurysms.

\section{Ruptured Intracranial Aneurysms}

For patients with ruptured intracranial aneurysms, 1-year mortality across all hospitals was $15.6 \%$, and varied from $4.7 \%$ to $21.4 \%$ among the hospitals ( $p<0.01$, Kruskal-Wallis test). Mortality did not change across year of admission ( $\mathrm{p}=0.21$, Kruskal-Wallis test). One-year mortality by mean hospital volume, adjusted for age, is shown in Fig. 2 upper.

Hazard ratios for 1-year mortality by hospital volume are given in Table 2. No clear relationship between hospital volume and mortality was observed in the unadjusted analyses. In the analyses adjusted for potential confounders, we observed a small statistically significant relationship between increasing hospital volumes and higher

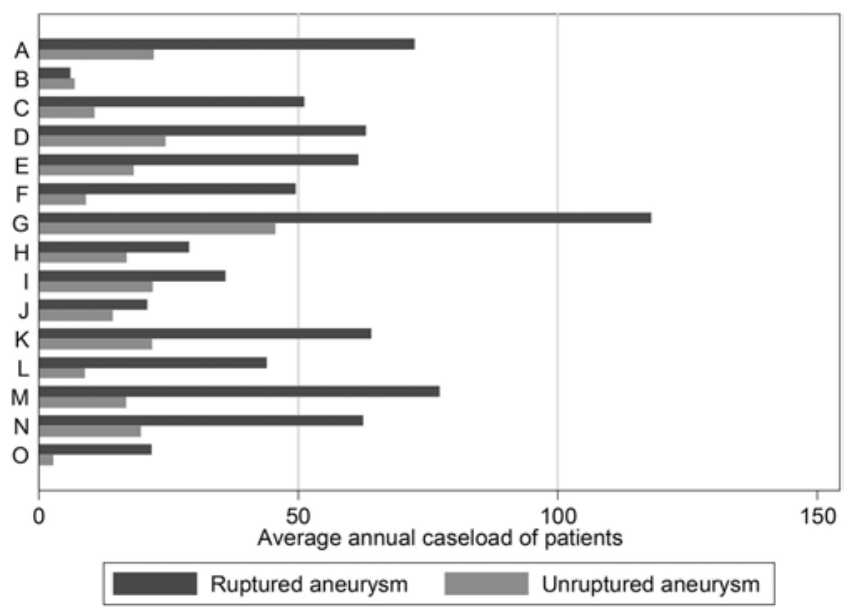

FIG. 1. Average annual volume of patients treated for intracranial aneurysms in Scandinavia from 2002 to 2010, according to hospital. Letters on the y-axis represent individual hospitals.

1 -year mortality $(p=0.04)$. Figure 3 upper shows ageadjusted cumulative mortality by hospital volume tertile.

\section{Unruptured Intracranial Aneurysm}

For patients with unruptured intracranial aneurysms, 1-year mortality across all hospitals was $2.7 \%$, and varied from $0 \%$ to $5.6 \%$ between the hospitals ( $p<0.01$, KruskalWallis test). Mortality did not change across year of admission ( $\mathrm{p}=0.98$, Kruskal-Wallis test). One-year mortality by mean hospital volume, adjusted for age, is given in Fig. 2 lower.

Hazard ratios for 1-year mortality by hospital volume are given in Table 2. We found an inverse relationship between hospital case volume and 1-year mortality in the unadjusted analyses. Similar HRs were observed after adjustment for potential confounders, but the association between hospital volume and 1-year mortality was no longer

TABLE 1. Patient characteristics according to hospital volume tertile

\begin{tabular}{|c|c|c|c|c|}
\hline \multirow[b]{2}{*}{ Characteristic } & \multicolumn{3}{|c|}{ Hospital Volume Tertile* } & \multirow[b]{2}{*}{$\mathrm{p}$ Value } \\
\hline & Low & Intermediate & High & \\
\hline \multicolumn{5}{|c|}{ Ruptured intracranial aneurysms } \\
\hline Patients & 510 & 2417 & 2846 & \\
\hline Mean age in yrs $( \pm S D)$ & $55.3 \pm 11.9$ & $56.2 \pm 11.9$ & $55.2 \pm 12.5$ & 0.01 \\
\hline Female sex (\%) & $321(63)$ & $1663(69)$ & $1919(67)$ & 0.04 \\
\hline Mean CCl ( \pm SD) & $0.25 \pm 0.49$ & $0.20 \pm 0.46$ & $0.21 \pm 0.49$ & 0.15 \\
\hline Surgically treated (\%) & $371(73)$ & $1104(46)$ & $1059(37)$ & $<0.01$ \\
\hline \multicolumn{5}{|c|}{ Unruptured intracranial aneurysms } \\
\hline Patients & 349 & 588 & 819 & \\
\hline Mean age in yrs $( \pm S D)$ & $56.2 \pm 10.5$ & $54.4 \pm 10.1$ & $54.4 \pm 10.4$ & 0.02 \\
\hline Female sex (\%) & $253(72)$ & $416(71)$ & $616(75)$ & 0.17 \\
\hline Mean CCI ( \pm SD) & $0.22 \pm 0.49$ & $0.14 \pm 0.40$ & $0.19 \pm 0.45$ & 0.01 \\
\hline Surgically treated (\%) & $181(52)$ & $231(39)$ & $405(49)$ & $<0.01$ \\
\hline
\end{tabular}

* Ruptured intracranial aneurysms: low-volume tertile $=6.2-36.0$ patients per year, intermediate-volume tertile $=43.8-62.4$ patients per year, high-volume tertile $=63.1-118.0$ patients per year. Unruptured intracranial aneurysms: low-volume tertile $=2.9-10.9$ patients per year, intermediate-volume tertile $=14.3-19.7$ patients per year, high-volume tertile $=21.9-45.6$ patients per year.

$\dagger$ Analysis of variance for continuous variables, chi-square test for categorical variables. 

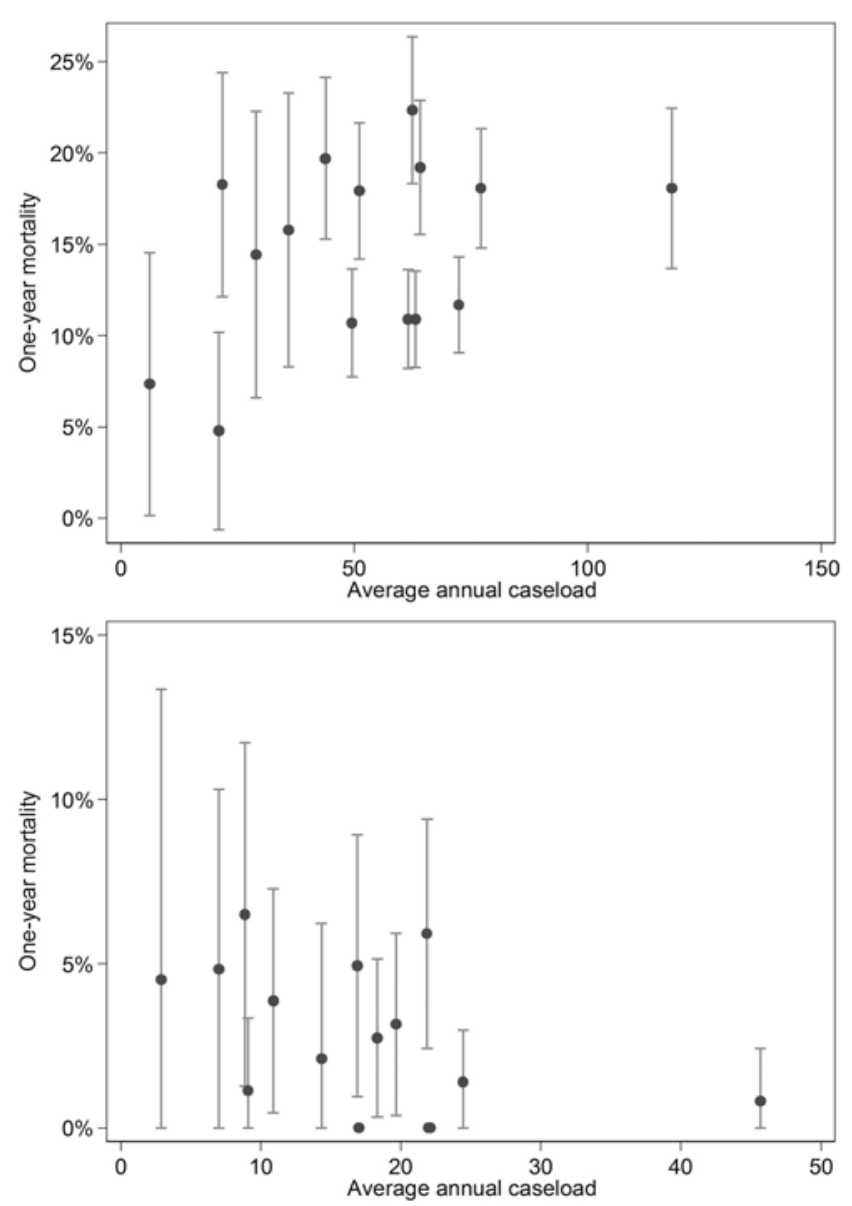

FIG. 2. Graphs of age-adjusted 1-year mortality after surgical and endovascular treatment for ruptured (upper) and unruptured (lower) intracranial aneurysms in Scandinavia from 2002 to 2010, according to average annual hospital volume. Whisker bars show $95 \%$ Cls.

statistically significant. Figure 3 lower shows age-adjusted cumulative mortality by hospital volume tertile.

\section{Between-Country Differences in Mortality}

Hazard ratios for 1-year mortality by country are given in Table 3. Mortality for both ruptured and unruptured aneurysms varied significantly between patients from Denmark, Norway, and Sweden. The between-country differences remained statistically significant after adjustment for potential confounders.

\section{Additional Analyses}

Analyses restricted to patients admitted between 2008 and 2010 provided similar directions of the effect size for the relationship between hospital volume and mortality after treatment compared with the original analyses. For ruptured intracranial aneurysms, the HR per 10-patient increase was 1.02 (95\% CI 0.98-1.06). For unruptured intracranial aneurysms, the HR per 10-patient increase was 0.48 (95\% CI 0.31-0.85).

Analyzes stratified by treatment modality (endovascular and surgical) found similar directions in the effect size for the relationship between hospital volume and mortality after treatment of both ruptured intracranial aneurysms
(HR per 10-patient increase in the surgical group was 1.04 [95\% CI 0.99-1.09] and in the endovascular group 1.02 [95\% CI 0.98-1.07]) and unruptured intracranial aneurysms (HR per 10-patient increase in the surgical group was 0.59 [95\% CI $0.29-1.23$ ] and in the endovascular group 0.79 [95\% CI $0.42-1.50]$ ).

\section{Discussion}

The main findings of the present study are that hospital volume was not consistently associated with 1-year mortality after treatment for ruptured intracranial aneurysms, whereas there was a trend toward lower mortality after treatment for unruptured intracranial aneurysms in high-volume hospitals. Furthermore, there were large differences in long-term (1-year) mortality across hospitals and between the 3 Scandinavian countries.

Our study adds to the literature by being the first to examine the relationship between hospital volume and longterm mortality after treatment of intracranial aneurysms. Most previous studies of hospital volume and mortality after treatment for unruptured and ruptured intracranial aneurysms have found lower mortality in high-volume compared with low-volume hospitals, but different definitions of "low-volume hospital" make direct comparison with our study difficult. . $^{1-4,7,8,13,14,16-18}$ All previous studies except 1 have reported mortality at discharge. The lower mortality in high-volume hospitals may therefore have been confounded, for instance, by differences in length of stay and discharge routines. . $^{1-4,7,8,12-14,16,18}$ Furthermore, all previous studies except 2 originated in the US and the analyses include data from hospitals where multidisciplinary neurosurgical care is likely to be less available or absent. ${ }^{1-4,7,8,13,14,16,18}$ Results from these studies may not be generalizable to health care systems in other countries where specialist neurosurgical services are centralized to tertiary regional hospitals with a defined population and patients are referred from smaller hospitals. A possible explanation for the differences between our results and those published from the US is that all treatments of intracranial aneurysms in Scandinavia are performed at academic hospitals by specialized cerebrovascular surgeons and interventional neuroradiologists, whereas neurosurgeons working in low-volume hospitals in the US may be more likely to be general neurosurgeons than specialized cerebrovascular surgeons.

Two previous studies have examined the relationship between hospital volume and outcome after aneurysm treatment in a health care system where specialist neurosurgical services are delivered at tertiary regional hospitals with a defined population. ${ }^{12,17}$ One study from Japan found no relationship between hospital volume and functional outcome (Glasgow Outcome Scale score) at discharge after treatment of ruptured and unruptured intracranial aneurysms. ${ }^{12}$ One study from the United Kingdom examined the relationship between hospital volume and 6-month mortality after (aneurysmal and nonaneurysmal) SAH. ${ }^{17}$ This study found a relationship between hospital volume and mortality, but the use of aggregated data, lack of adjustment for age or other prognostic factors, and inclusion of patients with nonaneurysmal SAH limit the generalizability of the results. 
TABLE 2. Hazard ratios for 1-year mortality after surgical and endovascular treatment for ruptured and unruptured intracranial aneurysms, according to annual volume of patients

\begin{tabular}{|c|c|c|c|c|c|}
\hline \multirow[b]{2}{*}{ Variable } & \multirow[b]{2}{*}{$\begin{array}{l}\text { No. of } \\
\text { Hospitals }\end{array}$} & \multirow[b]{2}{*}{$\begin{array}{l}\text { No. of Deaths/ } \\
\text { Patients }\end{array}$} & \multirow[b]{2}{*}{$\begin{array}{l}\text { 1-Yr Mortality } \\
(\%)\end{array}$} & \multicolumn{2}{|c|}{$\mathrm{HR}(95 \% \mathrm{Cl})$} \\
\hline & & & & Unadjusted & Adjusted $\dagger$ \\
\hline \multicolumn{6}{|l|}{ Ruptured intracranial aneurysms } \\
\hline \multicolumn{6}{|l|}{ Hospital volume tertile* } \\
\hline Low & 5 & $71 / 510$ & 13.9 & Reference & Reference \\
\hline Intermediate & 5 & $397 / 2417$ & 16.4 & $1.19(0.92-1.53)$ & $1.57(1.19-2.10)$ \\
\hline High & 5 & $431 / 2846$ & 15.1 & $1.10(0.85-1.41)$ & $1.24(1.05-1.81)$ \\
\hline$p$ value for trend & & & & 0.88 & 0.57 \\
\hline $\begin{array}{l}\text { Hospital volume (continuous variable), } \\
\text { per 10-patient increase }\end{array}$ & 15 & $899 / 5773$ & 15.6 & $1.02(0.99-1.05)$ & $1.04(1.00-1.07)$ \\
\hline \multicolumn{6}{|l|}{ Unruptured intracranial aneurysms* } \\
\hline \multicolumn{6}{|l|}{ Hospital volume tertile } \\
\hline Low & 5 & $16 / 349$ & 4.6 & Reference & Reference \\
\hline Intermediate & 5 & $17 / 588$ & 2.9 & $0.62(0.32-1.24)$ & $0.59(0.28-1.25)$ \\
\hline High & 5 & $15 / 819$ & 1.8 & $0.39(0.19-0.80)$ & $0.49(0.23-1.04)$ \\
\hline$p$ value for trend & & & & 0.01 & 0.07 \\
\hline $\begin{array}{l}\text { Hospital volume (continuous variable), } \\
\text { per } 10 \text {-patient increase }\end{array}$ & 15 & $48 / 1756$ & 2.7 & $0.59(0.40-0.88)$ & $0.69(0.42-1.10)$ \\
\hline
\end{tabular}

We found no consistent relationship in our study between hospital volume and mortality after treatment for ruptured intracranial aneurysms, but there was a trend toward lower mortality after treatment for unruptured intracranial aneurisms in high-volume hospitals. We believe a plausible explanation for this finding is that surgical experience is more directly associated with outcome after treatment for unruptured intracranial aneurysms because these patients are otherwise healthy and undergo planned surgery. In comparison, other factors that are not related to the surgical experience (such as severity of the SAH, prehospital care, and rehabilitation) may be more important contributors to outcome after treatment for ruptured intracranial aneurysms than hospital volume.

Our findings do not support centralization of treatment for ruptured intracranial aneurysms to high-volume centers. However, we found large between-hospital and between-country variations in mortality after surgical and endovascular treatment of both ruptured and unruptured intracranial aneurysms. The cause for this is unknown. Although the variations in mortality may reflect differences in quality of care, an equally possible explanation is differences in unmeasured prognostic factors (confounding by indication). ${ }^{15}$ For instance, some hospitals may have a more aggressive treatment approach for severe SAH (which has a poor prognosis) or for small, unruptured intracranial aneurysms (which has an excellent prognosis). Appropriate selection criteria for treatment are important, especially for unruptured intracranial aneurysms in which the decision to treat involves a tradeoff between the immediate surgical risk and the long-term risk of rupture. Studies from patient registries are unable to adjust for differences in selection to treatment as they lack data on important prognostic factors such as disease severity and aneurysm morphology. Prospective registries for evaluating patient outcomes after treatment for intracranial aneurysms are therefore highly warranted. Such a registry is currently being established in Norway.

The differences in mortality between hospitals should be interpreted with caution as some hospitals' samples were small and extreme outcomes (both high and low) are likely to occur randomly in small samples. ${ }^{20}$ From the patient's perspective, this may be of importance and favor undergoing treatment at larger-volume hospitals, as small sample sizes make it more difficult to determine the quality and safety of surgery in low-volume compared with high-volume hospitals. We also observed a large difference in the use of surgical treatment for ruptured intracranial aneurysms between high- and low-volume hospitals, which may reflect differences in the availability of interventional neuroradiology services 24 hours a day.

Our study has important limitations. First, all hospital discharge registries are prone to errors in coding. To reduce the risk of erroneous classification of cases, we used diagnosis codes, procedure codes, and whether the patient was admitted as an emergency to classify the cases as ruptured or unruptured intracranial aneurysms. Second, because of this approach, we did not include patients with intracranial aneurysms who did not undergo surgical or endovascular treatment. Selection criteria for treatment may vary across hospitals and could have influenced the results. Third, we calculated the CCI based on the secondary discharge diagnoses. These diagnoses likely do not fully reflect the patients' comorbidities. Fourth, we did not have data on functional outcome. Functional outcome may be of more interest than mortality, especially for patients 

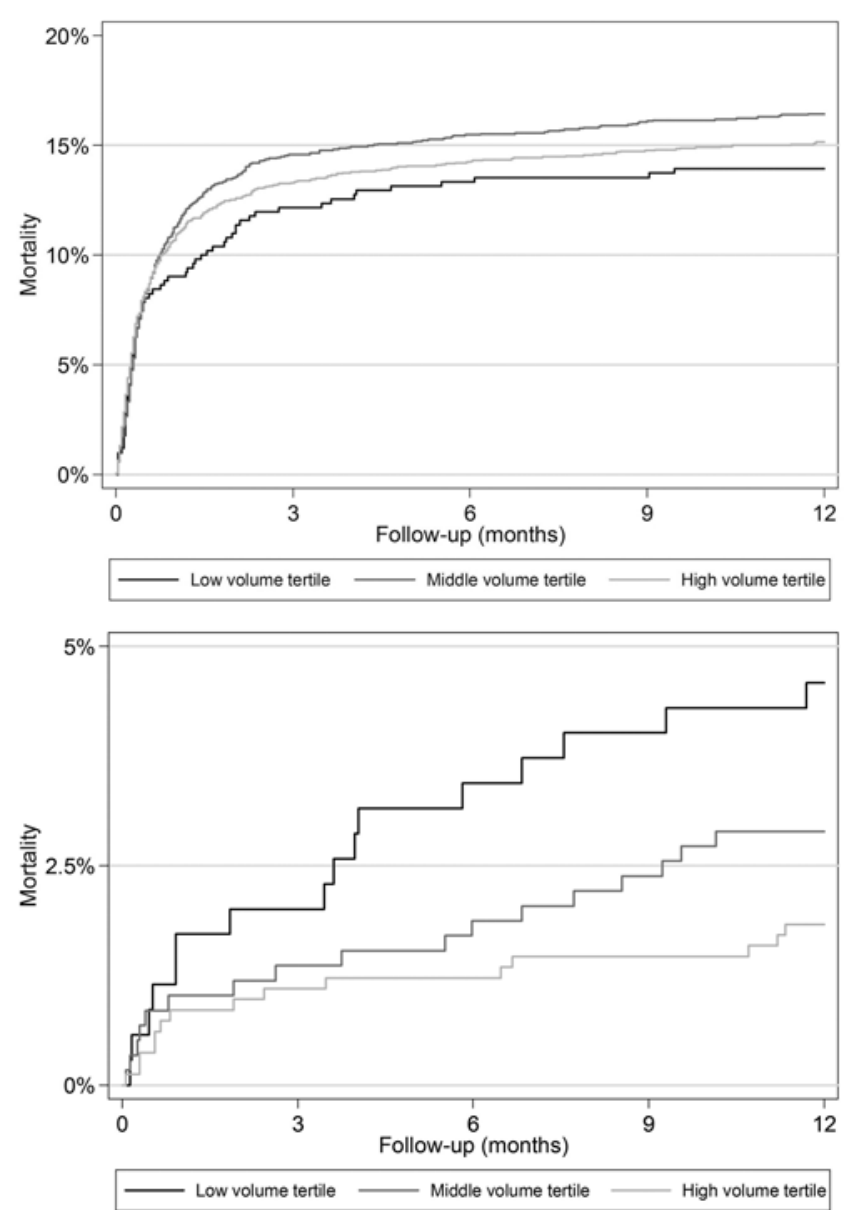

FIG. 3. Graphs of cumulative mortality in patients with ruptured (upper) and unruptured (lower) intracranial aneurysms, according to hospital volume tertile.

with unruptured intracranial aneurysms. Fifth, we used all-cause mortality and not disease-specific mortality as the outcome of interest. Although this may have attenuated the results, we believe all-cause mortality is of more interest than disease-specific mortality because it puts the magnitude into perspective for prospective decision making. Sixth, we did not have data on prognostic factors such as aneurysm location, size, morphology, and severity of the SAH (for instance, Hunt and Hess and Fisher grades).
Seventh, data on individual surgeons' volumes were not available. Eighth, we only had data available from Norway from 2008 onwards. However, analyses restricted to patients treated between 2008 and 2010 found similar effect size directions as the main analyses. Lastly, we did not have data on patients who emigrated from each country, but this is unlikely to have affected the results as less than $0.5 \%$ of the population emigrates annually. ${ }^{19}$

The limitations of our study are numerous, but similar limitations (use of hospital discharge data, lack of adjustment for prognostic factors such as aneurysm morphology and disease severity, and lack of data on functional outcome) pertain to all prior studies that examined the relationship between hospital case volume and mortality after aneurysm treatment, ${ }^{1-4,7,8,13,14,16-18}$ except one. ${ }^{12}$ Furthermore, although it is possible that more complex aneurysms are transferred to higher-volume centers, we believe this selection bias is less likely to affect the results from Scandinavia than those from the US because each hospital in Scandinavia treats a population in a defined geographic region. Although our findings may be controversial, they are consistent with the only previous study that has adjusted for disease severity. ${ }^{12}$ This study did not find a statistically significant relationship between hospital volume and outcome after treatment for ruptured intracranial aneurysms. ${ }^{12}$

Compared with previous studies, our study has important strengths, including a large, population-based sample with long-term follow-up through linkage with population registries. Furthermore, we used individual patient data and adjusted for age, sex, year of treatment, treatment type, and the CCI.

\section{Conclusions}

Our findings did not confirm a relationship between higher hospital volume and reduced long-term mortality after treatment of ruptured intracranial aneurysms. Furthermore, we observed significant differences in betweenhospital and between-country mortality rates. Prospective registries for evaluating patient outcomes after treatment for intracranial aneurysms are highly warranted.

\section{Acknowledgments}

Professor Bertil Romner (deceased) contributed to the design

TABLE 3. Hazard ratios for 1-year mortality after surgical and endovascular treatment for ruptured and unruptured intracranial aneurysms, according to country

\begin{tabular}{lccccc}
\hline \multicolumn{1}{c}{ Country } & No. of Hospitals & No. of Deaths/Patients & 1-Yr Mortality (\%) & Unadjusted HR & Adjusted HR* $^{*}$ \\
\hline Ruptured aneurysms & & & & & \\
\hline$\quad$ Sweden & 6 & $347 / 2736$ & 12.7 & Reference & Reference \\
\hline Norway & 4 & $98 / 612$ & 16.0 & $1.29(1.03-1.61)$ & $1.52(1.15-1.99)$ \\
\hline Denmark & 5 & $454 / 2425$ & 18.7 & $1.57(1.36-1.80)$ & $1.92(1.66-2.22)$ \\
\hline Unruptured aneurysms & & & & & \\
\hline$\quad$ Sweden & 6 & $17 / 827$ & 2.1 & Reference & Reference \\
\hline$\quad$ Norway & 4 & $2 / 297$ & 0.7 & $0.32(0.08-1.41)$ & $0.41(0.09-1.89)$ \\
\hline$\quad$ Denmark & 5 & $29 / 603$ & 4.8 & $2.27(1.25-4.13)$ & $2.89(1.53-5.40)$ \\
\hline
\end{tabular}

* Adjusted for hospital volume, patient age, patient sex, year of treatment, $\mathrm{CCl}$, and surgical treatment. 
and concept of the study. Anne-Marie Andersen at Sundhedsstyrelsen (Denmark), Inger Johanne Bakken at Helsedirektoratet (Norway), and Julius Collin at Socialstyrelsen (Sweden) extracted data from the patient registries and performed the linkage to the population registries.

\section{References}

1. Andaluz N, Zuccarello M: Recent trends in the treatment of cerebral aneurysms: analysis of a nationwide inpatient database. J Neurosurg 108:1163-1169, 2008

2. Bardach NS, Zhao S, Gress DR, Lawton MT, Johnston SC: Association between subarachnoid hemorrhage outcomes and number of cases treated at California hospitals. Stroke 33:1851-1856, 2002

3. Barker FG II, Amin-Hanjani S, Butler WE, Ogilvy CS, Carter BS: In-hospital mortality and morbidity after surgical treatment of unruptured intracranial aneurysms in the United States, 1996-2000: the effect of hospital and surgeon volume. Neurosurgery 52:995-1009, 2003

4. Berman MF, Solomon RA, Mayer SA, Johnston SC, Yung PP: Impact of hospital-related factors on outcome after treatment of cerebral aneurysms. Stroke 34:2200-2207, 2003

5. Birkmeyer JD, Siewers AE, Finlayson EVA, Stukel TA, Lucas FL, Batista I, et al: Hospital volume and surgical mortality in the United States. N Engl J Med 346:1128-1137, 2002

6. Charlson ME, Pompei P, Ales KL, MacKenzie CR: A new method of classifying prognostic comorbidity in longitudinal studies: development and validation. J Chronic Dis 40:373383, 1987

7. Cowan JA Jr, Dimick JB, Wainess RM, Upchurch GR Jr, Thompson BG: Outcomes after cerebral aneurysm clip occlusion in the United States: the need for evidence-based hospital referral. J Neurosurg 99:947-952, 2003

8. Cross DT III, Tirschwell DL, Clark MA, Tuden D, Derdeyn CP, Moran CJ, et al: Mortality rates after subarachnoid hemorrhage: variations according to hospital case volume in 18 states. J Neurosurg 99:810-817, 2003

9. Finks JF, Osborne NH, Birkmeyer JD: Trends in hospital volume and operative mortality for high-risk surgery. N Engl J Med 364:2128-2137, 2011

10. Gruen RL, Pitt V, Green S, Parkhill A, Campbell D, Jolley D: The effect of provider case volume on cancer mortality: systematic review and meta-analysis. CA Cancer J Clin 59:192-211, 2009

11. Halm EA, Lee C, Chassin MR: Is volume related to outcome in health care? A systematic review and methodologic critique of the literature. Ann Intern Med 137:511-520, 2002
12. Hattori N, Katayama Y, Abe T: Case volume does not correlate with outcome after cerebral aneurysm clipping: a nationwide study in Japan. Neurol Med Chir (Tokyo) 47:95-101, 2007

13. Hoh BL, Rabinov JD, Pryor JC, Carter BS, Barker FG II: Inhospital morbidity and mortality after endovascular treatment of unruptured intracranial aneurysms in the United States, 1996-2000: effect of hospital and physician volume. AJNR Am J Neuroradiol 24:1409-1420, 2003

14. Johnston SC: Effect of endovascular services and hospital volume on cerebral aneurysm treatment outcomes. Stroke 31:111-117, 2000

15. Johnston SC: Identifying confounding by indication through blinded prospective review. Am J Epidemiol 154:276-284, 2001

16. Leake CB, Brinjikji W, Kallmes DF, Cloft HJ: Increasing treatment of ruptured cerebral aneurysms at high-volume centers in the United States. J Neurosurg 115:1179-1183, 2011

17. McNeill L, English SW, Borg N, Matta BF, Menon DK: Effects of institutional caseload of subarachnoid hemorrhage on mortality: a secondary analysis of administrative data. Stroke 44:647-652, 2013

18. Solomon RA, Mayer SA, Tarmey JJ: Relationship between the volume of craniotomies for cerebral aneurysm performed at New York state hospitals and in-hospital mortality. Stroke 27:13-17, 1996

19. Statistics Norway: Immigration and emigration, 2012. (http://www.ssb.no/en/innvutv/) [Accessed April 28, 2015]

20. Tversky A, Kahneman D: Belief in the law of small numbers. Psychol Bull 76:105-110, 1971

\section{Author Contributions}

Conception and design: all authors. Acquisition of data: Lindekleiv. Analysis and interpretation of data: Lindekleiv, Førde. Drafting the article: Lindekleiv. Critically revising the article: all authors. Reviewed submitted version of manuscript: all authors. Approved the final version of the manuscript on behalf of all authors: Lindekleiv. Statistical analysis: Lindekleiv. Study supervision: Mathiesen, Førde, Wilsgaard, Ingebrigtsen.

\section{Correspondence}

Haakon Lindekleiv, Department of Community Medicine, Faculty of Health Sciences, University of Troms $\varnothing$, N-9037 Troms $\varnothing$, Norway.email: haakon.lindekleiv@gmail.com. 